\title{
EFEITO DA TEMPERATURA NA ADSORÇÃO DE AZUL DE METILENO USANDO BAGAÇO DE MALTE IN NATURA
}

\author{
R. C. A. LIMA ${ }^{1}$, K. ZAPELÃO ${ }^{1}$, D. F. S. PARLADORE ${ }^{1}$ e A. ANSCHAU ${ }^{1}$ \\ ${ }^{1}$ Universidade Tecnológica Federal do Paraná, Engenharia de Bioprocessos e Biotecnologia \\ E-mail para contato: andreiaanschau@utfpr.edu.br
}

\begin{abstract}
RESUMO - Os corantes presentes nos efluentes das indústrias causam inúmeros danos ao ambiente onde é liberado. Desse modo, as indústrias buscam uma forma econômica e sustentável de fazer o tratamento de forma eficaz. O objetivo deste trabalho foi estudar a influência da temperatura na remoção do azul de metileno, considerado como adsorbato modelo, utilizando bagaço de malte in natura moído a 40 mesh. Utilizou-se a bagaço de malte na granulometria de 40 mesh. O experimento foi realizado nas temperaturas de 25,35 e $45^{\circ} \mathrm{C}$ e o $\mathrm{pH}$ da solução de corante foi de 6,65. Os resultados foram analisados estatisticamente por análise de variância (ANOVA) e teste Tukey, com teste de confiabilidade em torno de $95 \%$. Observou-se que houve diferença estatisticamente significativa entre as diferentes temperaturas. Os experimentos conduzidos a $25^{\circ} \mathrm{C}$ e $35^{\circ} \mathrm{C}$ resultaram em remoção acima de $95 \%$ de corante, ao passo que à temperatura de $45^{\circ} \mathrm{C}$ foi obtida uma remoção inferior. Isto demonstra que é possível obter uma remoção significativa nas temperaturas de $35^{\circ} \mathrm{C}$ e na temperatura ambiente de $25^{\circ} \mathrm{C}$, possibilitando um custo menor para aplicações na remoção do corante.
\end{abstract}

\section{INTRODUÇÃO}

A presença de corantes nos corpos hídricos afeta a coloração da água resultando na redução da penetração de luz (Alkan et al., 2008), diminuindo assim a eficiência da fotossíntese em plantas aquáticas e, portanto, gerando um efeito adverso no seu crescimento (Al- Degs et al., 2000).

As indústrias têxteis são as principais responsáveis pela presença de corantes no meio ambiente, visto que, mais de $60 \%$ dos corantes produzidos mundialmente são utilizados no beneficiamento têxtil e, deste total, em consequência das perdas do processo, mais da metade acaba sendo despejada em corpos d'água sem nenhum tipo de tratamento afirmou Khadhraoui et al., (2009).

Oliveira et al. (2013) concluiu que apesar do azul de metileno não ser tóxico quanto à presença de metais pesados, a exposição aguda pode causar efeitos prejudiciais à saúde como aumento do batimento cardíaco, dor de cabeça intensa, náuseas, vômitos, diarreia e necrose do tecido humano. Muitos métodos físicos e químicos são empregados para o tratamento de efluentes contendo corantes, tais como, adsorção, eletroquímica, precipitação, filtração, ozonização entre outros, sendo, no entanto, a adsorção o processo de tratamento mais utilizado. 
Os sólidos apresentam a propriedade de reter moléculas em sua superfície e esta propriedade pode ser bastante acentuada no caso de materiais porosos ou finamente divididos, o carvão ativado a nível industrial pode ser utilizado para o tratamento de efluentes e purificação da água.

O bagaço de malte possui características para ser um bom adsorvente por possuir alto teor de carbono. Nakamura et al. (2010) verificou que o bagaço de malte seco se apresentou como matéria-prima de grande potencial para a produção de carvão ativado. Além de ser um subproduto da indústria cervejeira, é uma matéria prima de baixo custo.

De acordo com Orsoletta (2015) o uso de adsorventes de baixo custo e ecologicamente corretos, vem sendo pesquisados como alternativa na substituição de métodos de custo mais elevado na remoção em corantes de águas residuais, como tratamentos com reagentes químicos.

O objetivo deste trabalho foi estudar a influência da temperatura na remoção do adsorbato modelo azul de metileno utilizando bagaço de malte in natura moído a 40 mesh. Os resultados foram analisados estatisticamente e a comparação de médias foi feita pelo teste de Tukey a 5\% de probabilidade de erro.

\section{MATERIAL E MÉTODOS}

\subsection{Adsorvente}

O bagaço de malte foi cedido pela micro cervejeira Schaf Bier, localizada na cidade de Francisco Beltrão, Paraná, Brasil. Para o preparo do bagaço de malte, o mesmo foi submetido à lavagem com água corrente, para a remoção das impurezas, seguido de secagem em estufa. Após, foi feita a moagem dos grãos utilizando moinho de facas, para a obtenção de granulometria de 40 mesh, previamente estabelecida.

\subsection{Procedimento Experimental}

Os ensaios de adsorção em sistema em batelada foram realizados adicionando-se 1,2 g do adsorvente em $200 \mathrm{~mL}$ de solução de azul de metileno (100 mg/L), em frascos Erlenmeyers de $250 \mathrm{~mL}$, resultando em uma dosagem de adsorvente de $6 \mathrm{~g} / \mathrm{L}$ em base seca. Todos os ensaios foram feitos em triplicata e o $\mathrm{pH}$ ajustado para 6,65 de acordo com os resultados da análise de ponto de carga zero. Os frascos Erlenmeyers foram mantidos em Shaker a $100 \mathrm{rpm}$, por 24 horas às temperaturas de 25,35 e $45^{\circ} \mathrm{C}$. Amostras foram retiradas em intervalos de tempo prédeterminados, centrifugadas e quantificadas quanto à porcentagem de remoção de corante através de análises em triplicata em espectrofotômetro a $665 \mathrm{~nm}$, a partir de uma curva de calibração. 


\subsection{Equilíbrio de Adsorção}

A quantidade de corante adsorvida no equilíbrio foi calculada utilizando-se a Equação 1 sendo que $q_{\text {eq }}$ é a quantidade de corante adsorvida no equilíbrio $(\mathrm{mg} / \mathrm{g}), \mathrm{C}_{0}$ é a concentração inicial de corante na fase líquida $(\mathrm{mg} / \mathrm{L}), \mathrm{C}_{\text {eq }}$ a concentração de corante na fase líquida no equilíbrio (mg/L), V o volume da solução de corante (L) e m a massa de bagaço de malte in natura $(\mathrm{g})$ :

$$
q e q=[(C o-C e q) x V] m
$$

\subsection{Análise Estatística}

Os resultados foram analisados estatisticamente, utilizando-se o software STATISTICA 7.0 (Analytical Software, Tallahassee, FL, USA). A comparação de médias foi feita pelo teste de Tukey a $5 \%$ de probabilidade de erro.

\section{RESULTADOS E DISCUSSÃO}

A Tabela 1 apresenta os resultados dos experimentos a $25^{\circ} \mathrm{C}, 35^{\circ} \mathrm{C}$ e $45^{\circ} \mathrm{C}$ e respectivos resultados de remoção $(\%)$ e $\mathrm{q}_{\mathrm{eq}}(\mathrm{mg} / \mathrm{g})$ em $10 \mathrm{~h}$ e $24 \mathrm{~h}$. A quantidade de corante adsorvida no equilíbrio variou de 15,64 a 16,09 mg/g para todas as condições estudadas.

Tabela 1 - Ensaios a $25^{\circ} \mathrm{C}, 35^{\circ} \mathrm{C}$ e $45^{\circ} \mathrm{C}$ e resultados de remoção (\%) e qeq $(\mathrm{mg} / \mathrm{g})$

\begin{tabular}{|c|c|c|c|}
\hline \multicolumn{2}{|c|}{ Ensaio } & Remoção (\%) & Qeq (mg/g) \\
\hline \hline \multirow{3}{*}{$10 \mathrm{~h}$} & $25^{\circ} \mathrm{C}$ & $95,04 \pm 0,15$ & $15,84 \pm 0,03$ \\
\cline { 2 - 4 } & $35^{\circ} \mathrm{C}$ & $95,35 \pm 0,38$ & $15,92 \pm 0,06$ \\
\cline { 2 - 4 } & $45^{\circ} \mathrm{C}$ & $93,89 \pm 0,07$ & $15,64 \pm 0,01$ \\
\hline \multirow{3}{*}{$24 \mathrm{~h}$} & $25^{\circ} \mathrm{C}$ & $95,16 \pm 0,20$ & $15,88 \pm 0,33$ \\
\cline { 2 - 4 } & $35^{\circ} \mathrm{C}$ & $96,70 \pm 0,50$ & $16,09 \pm 0,08$ \\
\cline { 2 - 4 } & $45^{\circ} \mathrm{C}$ & $94,58 \pm 0,06$ & $15,77 \pm 0,01$ \\
\hline
\end{tabular}

A Figura 1 apresenta os valores de desvio das diferentes temperaturas estudadas no tempo de 10 horas e 24 horas. Este estudo foi considerado segundo o teste de Tukey a 95\% de confiabilidade. Como pode ser observado, para as mesmas temperaturas, não há diferença estatisticamente significativa para os tempos 10 e $24 \mathrm{~h}$. Assim, verifica-se que o sistema entrou em equilíbrio em $10 \mathrm{~h}$ para as temperaturas de 25,35 e $45^{\circ} \mathrm{C}$, podendo-se finalizar a reação nesse tempo. $\mathrm{O}$ experimento conduzido a $35^{\circ} \mathrm{C}$ por $24 \mathrm{~h}$ apresentou resultado estatisticamente superior em relação aos demais. Verifica-se ainda que quando utilizada a temperatura de $25^{\circ} \mathrm{C}$, a mesma não apresentou diferença estatisticamente significativa em relação às demais condições. Com isso, conclui-se que a temperatura ambiente é eficiente na remoção de azul de metileno utilizando bagaço de malte in natura.

Figura 1- Porcentagem de Remoção a $25^{\circ} \mathrm{C}, 35^{\circ} \mathrm{C}$ e $45^{\circ} \mathrm{C}$ em $10 \mathrm{~h}$ e $24 \mathrm{~h}$. 


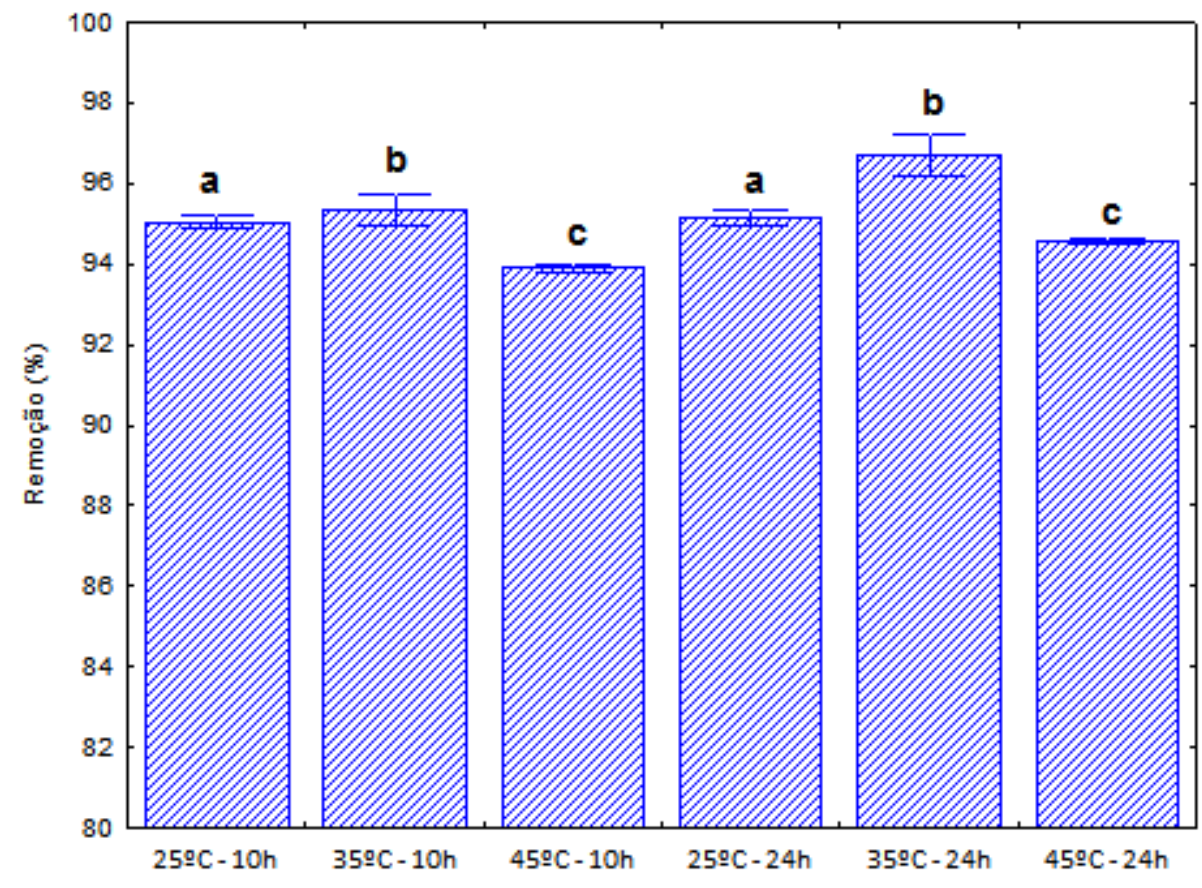

Gonçalves et al (2014) avaliaram a adsorção de solução de azul de metileno (200 mg/L) através do bagaço de malte a $30^{\circ} \mathrm{C}$, durante 48 horas. Os autores observaram que as propriedades adsortivas dos carvões ativados, indicadas pelo índice de descoloração de azul de metileno, foram aumentadas conforme o aumento no tempo de ativação sob a temperatura de $30^{\circ} \mathrm{C}$. A amostra de carvão ativado no ponto $6 \mathrm{~h}$ foi a que apresentou melhor desempenho, alcançando um índice de descoloração da solução de 99,97\%.

Silva (2005) estudou diferentes temperaturas na adsorção do azul de metileno com serragem de Pinus elliottii e concluiu que o aumento da temperatura causou uma diminuição na quantidade máxima adsorvida, porém aumentou a velocidade de adsorção, diminuindo o tempo para atingir o equilíbrio. Em $25^{\circ} \mathrm{C}$, demorou apenas 34 minutos para que atingisse o equilíbrio tendo $99,7 \%$ de remoção do corante.

Gouveia (2013) com base em dados de Li et al., (2011), observou que para o corante azul de metileno, os resultados mais satisfatórios foram em temperatura de $60{ }^{\circ} \mathrm{C}$ com eficiência de $60,9 \%$ de remoção.

Diante dos trabalhos apresentados, o bagaço de malte apresenta-se como uma matériaprima promissora na adsorção de azul de metileno em temperatura ambiente, visto que em poucas horas o percentual de remoção de corante atinge o equilíbrio. Tendo em vista que estatisticamente houve somente uma pequena diferença significativa entre a maior e a menor temperatura, a temperatura ambiente será fixada para os próximos estudos, pois dessa forma não são necessários gastos com energia e equipamentos para aquecer o fluido durante seu tratamento.

\section{CONCLUSÃO}

O bagaço de malte in natura, mostrou-se eficiente na remoção de azul de metileno nas diferentes temperaturas estudadas. Como o experimento conduzido a temperatura $25^{\circ} \mathrm{C}$ 
apresentou baixa diferença estatisticamente significativa em relação às demais condições, a temperatura ambiente foi definida para futuros estudos. Trabalhar com o adsorvente à temperatura ambiente é bem mais vantajoso para uma indústria do que em temperaturas elevadas, pois dessa forma não são necessários gastos com energia e equipamentos para aquecer o fluido durante seu tratamento.

\section{REFERÊNCIAS}

AL-DEGS, Y.; KHRAISHEH, M.A.M.; ALLEN, S.J.; AHMAD, M. N. 2000. Effect of carbon surface chemistry on the removal of reactive dyes from textile effluent. Water Research. Vol 34, p. 927-935

ALKAN, M.; DOGAN, M.; TURHAN, Y.; DEMIRBAS, O.; TURAN, P. 2008. Adsorption kinetics and mechanism of maxilon blue $5 G$ dye on sepiolite from aqueous solutions. Chemical Engineering Journal. Vol 139, p. 213-223.

GONÇALVES, G. C.; NAKAMURA, P. K.; VEIT, M. T.; FIAMETTI, K. G.; SILVA, G. M. C. XX Produção E Caracterização De Carvão Ativado Granulado E Bio-Óleo a Partir Dos Resíduos Da Industria Cervejeira.COBEQ, p. 1-9, 2010

GOUVEIA, A. DE F. REMOÇÃO DE AZUL DE METILENO E VERMELHO REMAZOL POR ADSORÇÃO UTILIZANDO LODO DE ESTAÇÃO DE TRATAMENTO DE ÁGUA E CARVÃO ATIVADO GRANULAR. Universidade Tecnológica do Paraná, 2013.

KHADHRAOUI, M.; TRABELSI, H.; KSIBI, M.; BOUGUERRA, S.; ELLEUCH, B. 2009. Discoloration and detoxicification of a Congo red dye solution by means of ozone treatment for a possible water reuse. Journal of Hazardous Materials. Vol 161, p. 974981.

OLIVEIRA, S. P.; SILVA, W. L. L.; VIANA, R. R. Avaliação da capacidade de adsorção do corante azul de metileno em soluçãoes aquosas em caulinita natural e intercalada com acetato de potássio. Cerâmica, v. 59, n. 350, p. 338-344, 2013.

ORSOLETTA, G. D.; DALLA, R. Utilizando bagaço de cana-de-açúcar por meio de planejamento fatorial 2 3. Synergismus scyent i f ica UTFPR, v. 10, n. 1, p. 74-80, 2015.

SILVA, A. T. DA.; Influência da temperatura na adsorção do corante azul de metileno utilizando serragem de Pinus elliottii como um adsorvente alternativo: um modelo para o tratamento de efluentes têxteis. Universidade Federal de Santa Catarina, p. 1-45, 2005.

WHEN-HONG, L. et al. Preparation and utilization of sludge-based activated carbon for the adsorption of dyes from aqueous solutions. Journal Chemical Engineering. 171. 320- 327. 2011. 